\title{
Use of UAV or remotely piloted aircraft and forward-looking infrared in forest, rural and wildland fire management: evaluation using simple economic analysis
}

\author{
B. R. Christensen
}

\begin{abstract}
Background: Investment in emerging technologies may contribute to a reduction in the suppression costs of wildfires, and is thus worth careful consideration and trialling by researchers and managers. This investigation looked at the potential incorporation of a newly emerging remote sensing technology, remotely piloted aircraft and forward-looking infrared investigated using a cost-benefit analysis approach.
\end{abstract}

Methods: An online survey-based approach targeting subject matter experts in wildland fire management and unmanned aircraft was used to evaluate the percentage change in the effectiveness of five different management scenarios using remotely piloted aircraft and forward-looking infrared. The most commonly accepted economic model in wildland fire management was adapted to determine the net value change between the five scenarios.

Results: The benefits of incorporated unmanned aerial vehicles (UAV) or remotely piloted aircraft and forward-looking infrared were measured as the reduction in cost-opportunity of helicopter use, and were estimated as an average of $\$ 548$ per fire (where the average cost of fires was $\$ 1767$ ) or a $31 \%$ cost saving on total suppression costs. The return on investment of such technology was estimated at 24 fires, whereas the return of investment of the existing thermal camera/helicopter use occurred after 160 fires.

Conclusions: The incorporation of remotely piloted aircraft and forward-looking infrared if implemented and managed appropriately, could well improve the cost effectiveness of the current forest, rural and wildland fire fighting efforts. The inherent uncertainty on such unevaluated technology (the combination of remotely piloted aircraft and forward-looking infrared) was addressed by adding stochastic variability and a triangular probability distribution approximation. Key management issues and recommendations are identified such as; greater use of current thermal camera equipment where possible, taking a project management based approach for further testing of remotely piloted aircraft and other emerging technologies, and the improved financial recording and reporting of fire management efforts.

Keywords: Emerging technology; Forest fire; Wildland fire; Rural fire; Remotely piloted aircraft (RPA); "Drones”; Forward Looking Infrared (FLIR); Cost benefit analysis

Correspondence: bchristensen@doc.govt.nz

(Threats)-Conservation-Related Fire Research, Department of Conservation,

99 Sala Street, Rotorua, New Zealand 


\section{Background}

Use of remotely piloted aircraft (RPA $\left.{ }^{1}\right)$, also known as unmanned aerial vehicles (UAV)/radio-controlled aircraft, 'drones' or semi/fully autonomous vehicles, is a rapidly developing area that lends itself to wildland rural fire management (Rango et al. 2006; Kumar et al. 2011; Royo et al. 2011; Merino et al. 2012). Royo et al. (2011) went further in stating that such systems provide significant advantages over current aerial means of fire fighting in terms of flexibility, precision, cost, and safety. The quantification of RPA cost and comparisons to established methods such as helicopter use, and modelling the return on investment (including reducing safety risks) for wildland rural fire management is an area that requires investigation. Similar to the growth in information technology, this is an area useful to consider in terms of organisational capability and potential uptake.

Economic theory has played an important role in establishing wildland fire management budgets in the USA (Donovan and Rideout 2003; Ganewatta 2008) and in Australia (Florec et al. 2012). As concern over growing mega-fires and the trend of suppression expenditures has increased in the USA and Australia, so has the use of economic theory to maximise social benefits by optimally allocating resources in wildland fire management (Ganewatta 2008). Laupacis et al. (1992) noted that the ideal time to evaluate the costeffectiveness of a technology is before its widespread introduction. Such economic analysis has been done previously with the established geospatial technologies for wildfire management, producing a more efficient use of resources results (Hesseln et al. 2010). The industry is now in a similar situation with emerging technologies such as RPAs. The specific research question is as follows:

1. What is the potential cost-opportunity of using an emerging technology in comparison to the current wildland rural fire management approach used in New Zealand?

\section{Methods}

\section{Specialist (expert elicitation) viewpoints}

An expert elicitation method was used to retrieve and synthesise the opinions from members of relevant Linked-in ${ }^{\text {тM }}$ networks that would hold a degree of experience and knowledge in RPAs, technology, their systems and wildland fire management. Expert elicitation, a method of coalescing knowledge and combining judgements (Runge et al. 2011) is often used where data is expensive, limited or unreliable, such as environmental health management, nuclear waste production and its management, and emerging energy production technology (Knol et al. 2010; Anadón et al. 2012). A survey request on December 9th 2013 was put to the members of Linked-in ${ }^{\text {тм }}$ networks (Wildland Fire Management/Firewise/Fire Adapted Communities, Fire Behaviour Analysts, the Wildland Fire Network, and the Unmanned Aviation Group). It was assumed that the membership of these networks would have the greatest accumulation of expert knowledge in the field of wildland fire management, RPA use etc. As of January 6th 2014 a total of 11 individuals responded to this survey request. They were asked to give their opinion on expected potential changes in forest and rural fire management (see Table 2) in accordance with the technological investment scenarios outlined in Table 1. For example one of the questions was as follows;

- Please consider the suppression reduction from using (or potentially using) thermal or infrared cameras in fire management (for example its use in mop-ups, cold trailing, etc.). What in your considered opinion is the respective percentage costbenefits occurring from using a Thermal or IR (Infrared) imaging device compared to the total suppression costs? (any number including negative values can also be used). For example:

1. Highest value (highest percentage cost saving in using thermal or IR imaging devices)

2. Lowest value (lowest percentage cost saving in using thermal or IR imaging devices)

3. Most likely value (most likely cost saving in using thermal or IR imaging devices)

Table 1 Summary of scenario parameters

\begin{tabular}{ll}
\hline Scenario/parameters & Values \\
\hline Scenarios: & $\begin{array}{l}0-\text { Pre-thermal camera costs, 1-Thermal camera/helicopter costs, 2-Potential RPA use-25 \%, 3-Potential RPA } \\
\text { use-50 \%, 4-Potential RPA use-100 \% } \\
\text { Suppression reduction using (or potentially using) thermal or infrared cameras in fire management, Area burned, } \\
\text { fire suppression cost, fatalities, injuries }\end{array}$ \\
Time: & $\begin{array}{l}0-10 \text { years projection } \\
\text { Discount rate: }\end{array}$ \\
Fires/year: & $1-20,25$ \\
Numbers of units: & $1,2,3,5,10$ \\
\hline
\end{tabular}




\section{Cost-benefit analysis approach}

Cost-benefit analysis (CBA) is used to evaluate the known or perceived costs and benefits of a number of scenarios including the status quo-or current approach. It is a monetary-based framework that identifies the scenario with the best return on investment, or best Net Present Value (NPV). NPV is the sum of the present value of future cash flows minus the purchase price, and/or management cost for a given scenario (Hyytiäinen and Haight 2010). The CBA approach broadly followed the framework as described by the New Zealand Treasury (The Treasury 2005) and Gould et al. (2013), although for wildland fires, quantifying all of the benefits or reduced losses is impossible (Gould et al. 2013). The available pre-suppression costs (i.e. equipment purchase costs) and known suppression costs were based on Wu et al. (2009) analysis.

\section{$C+N V C$ model}

Donovan and Rideout's (2003) $C+N V C$ model $^{2}$ has become the standard or at least most commonly accepted model in evaluating wildland rural fire management programmes (Ganewatta 2008; Gebert et al. 2008; Florec et al. 2012). Lankoandé (2005) used this model and estimated that every (US) dollar invested in pre-suppression efforts reduces suppression expenditures by 3.76 dollars. The $C+N V C$ model is particularly useful for production forestry (including native forest that is available for logging). The $C+$ NVC model (as utilised by Wu et al. 2009) was used to evaluate the incorporation of thermal camera and RPA technology into the New Zealand fire management 'toolkit'.

For the purposes of this article, the costs and benefits of using new technology focused on the fire suppression cost component, e.g. equipment cost and use, and the respective opportunity costs. These values were detailed in terms of a current baseline situation, i.e. monitoring of fire management conditions using helicopters and mannedthermal cameras. The specific $C+N V C$ model used (see below) follows Wu et al. (2009) as the primary economic evaluation of wildfire management costs, benefits and damages within New Zealand to date. They investigated the wider costs of wildfire management, and specifically compared the net present values of resource outputs and management costs between fires occurring and not occurring. For example:

- $C$ is the total sum of the technology (i.e. equipment) costs.

- $N V C$ is the total sum and net present value of all specific technology costs associated with wildfires management within New Zealand, and equals the net value change (i.e. opportunity cost) between different scenarios.
Thus the specific model as used in this paper is;

$$
N V C=N P V a-N P V b
$$

Where

$N V C$ net value change

$N P V a$ net present value for scenario $a$

$N P V b$ net present value for scenario $b$

For the purpose of this analysis, the cost and benefits of thermal cameras, RPA, helicopter use related to wildland fire activities, were compared with the context of the baseline situation (i.e. no thermal camera use). Variable suppression costs are a subset of those identified by Gould et al. (2013), and are as follows:

- fire suppression costs,

- area burned (ha),

- numbers of fatalities,

- number of injuries.

Costs were considered to be number of dollars (NZD at 2013 third quarter value (2013: 3Q)) to purchase thermal cameras, potential costs for RPAs and FLIR systems or miniaturised thermal cameras and helicopter running costs. It was assumed that the FLIR capabilities were effectively equivalent in terms of rural fire management use to that of the current Department of Conservation (DOC) thermal cameras. The baseline was then compared against the cost and benefit of thermal camera use currently either by using a helicopter or on foot, miniaturised FLIR thermal cameras in three different scenarios. It is expected that increased hot spot detection for example will reduce the "mop-up" costs for organisations, claims on the National Rural Fire Authority rural fire fund, and hence cost to the taxpayers of New Zealand. A Monte Carlo simulation method of 1000 repetitions was used to determine a distribution of Net Present Value (NPV) for each scenario.

The fire suppression costs are of key interest in terms of specific case study analysis for this paper. Safety is a key concern in wildland rural fire management, though the quantification of safety costs is subject to significant debate. Sixteen people have died in wildland rural fire management within New Zealand over last 40 years (data from http://www.ruralfirehistory.org.nz/fire_fighters.htm). Of these, four have died in helicopter crashes. The value of human life in the literature is generally noted as the Value of Statistical Life (VoSL). While also subject to significant debate, this does give a monetary value to a human life that can be utilised for economic analysis (MOT 2008). New Zealand's Ministry of Transport has produced a "willingness to pay" value for road safety (injury and death prevention) within the Transport Sector 
(comprising Road, Aviation and Maritime sectors). This was listed as \$2 million in 1991 dollar terms; which equates $\$ 3.71 \mathrm{~m}$ in 2013: 3Q. Injuries to wildland rural fire fighters, and the details and costs of these have been published, e.g. within the Buckland Crossing Fire burnover 24 March 1998 (Pearce et al. 2004), though up-to-date data is difficult to source. Injuries were identified as 0.4$10 \%$ of VoSL (MOT 2008; Wren and Barrell 2010).

\section{Wildfire management costs}

The wildfire management costs were compiled from a variety of sources, chiefly from the annual reports from New Zealand Fire Service (NZFS) and DOC, and DOC financial records. The DOC annual expenditure on fire management averaged around $7 \%(\$ 11.4 \mathrm{M})$ of the total natural heritage expenditure $(\$ 164.0 \mathrm{M})$. The fire-related DOC helicopter costs for the time period 2009/10-2012/13 averaged around $4 \%$ ( $\$ 367 \mathrm{k}$ ) of the total fire control expenditure.

\section{Technological investment scenarios}

The investment of new technology has both costs and benefits. In order to examine the potential benefit in dollars for using RPAs for monitoring, a current "status quo" scenario was compared with three other "alternative" scenarios. The status quo described the current use of helicopters and thermal cameras, whereas the alternative scenarios looked at three percentages $(25,50$, and $100 \%)$ of potential RPA incorporation into fire management. All scenarios utilized specialist (expert) opinions and cost information sourced from DOC financial information (for "status quo" scenario 1). The thermal camera use over the last 3 years (February 2011 onwards) was sourced from the thermal camera worksheets (DOC unpubl. data). These also gave the number of fires, and amount of time used. This equated to $2.5 \mathrm{~h}$ per unit per year at active fire fighting, a total of $22 \mathrm{~h}$ for the three units in the last 3 years since they were purchased, or $7.9 \mathrm{~h}$ use per year in total). Further cost information was sourced from specific RPA and FLIR websites (http://conservationdrones.org/, http:// www.flir.com/NZ/, and http://multiwicopter.com/).

Cost information sourced from DOC financial reports, and RPA-FLIR costs. DOC currently has three thermal cameras (P620, I60 models) with total purchase costs of approx $\$ 106 \mathrm{k}$.

The key assumption is that the FLIR technology is comparable in terms of hotspot detection as the existing thermal camera capabilities. The potential outcomes in using RPA and FLIR technology may include quicker response times, greater aerial water and resources deployment, less repeat "mop-up" work, quicker demoblisation of resources, etc.-all of which reduce suppression expenditure on wildland rural fires.

\section{Modelling of costs}

Fire management costs are quite variable over time, with the average percentage expenditure for DOC of fire management costs (e.g. pre-suppression, suppression) is generally $7 \%$ (of the total natural heritage expenditures of DOC for each of the previous six financial years). As some costs occurred over different years (e.g. Thermal imaging camera costs, total fire expenditures, current RPA cost, etc.), in order to reduce inflation-based bias, all costs are expressed in 2013 Q3 figures using the reserve bank inflation calculator (http://www.rbnz.govt.nz/ monetary_policy/inflation_calculator/) in order to minimise any inflation ambiguity. A summary of the parameters tested for each scenario is presented in Table 1. As the cost data was not considered to be as detailed as possible (e.g. there could be more appropriate or cheaper RPA-FLIR systems available-such as the recent iphone/ FLIR app/add-on (http://www.gizmag.com/flir-iphonethermal-imaging/30447/ accessed 20/01/2014). unknown actual thermal/FLIR returns, unknown actual discount rates), variability was included into each cost benefit analysis, by running the NPV calculations using a Monte Carlo simulation model (a total of 5000 simulations).

As indicated above, there is general variability on the annual DOC expenditure relating to fire management. As the actual benefits relating to incorporating any new technology is generally unknown, the combination of different annual costs (expenditure) and the indefinite benefits creates a clear degree of uncertainty for an evaluation. This uncertainty was addressed using a stochastic process, where the key cost and benefit values were transformed using a randomisation process (triangular distribution model), and then run under a Monte Carlo simulation model. As the input information was limited, a subjective probability distribution was chosen to approximate the economic costs. A triangular distribution model (following Gould et al. 2013) was chosen as an approximation of the variables relating to the above scenarios. The following issues supported the choice of the triangular distribution model:

1. There is currently limited detailed and assessable data (Garthwaite et al. 2005) on the exact costs of wildfire management in New Zealand,

2. Unknown actual benefits resulting from thermal camera and RPA use,

3. It is a relatively simple elicitation method (Garthwaite et al. 2005), and is intuitive for survey participants (van Dorp and Kotz 2002).

In addition to the above identified issues, the triangular distribution model is often applied in business decision making, risk analysis and project management. 
Table 2 Elicitation summary of the experts' average lowest, highest and most likely (bold) mean and range (in italics) estimates (to $1 \mathrm{dp}$ ) of cost-benefit percentage change in wildland fire management activities for status quo (i.e. helicopters) and potential RPA use in monitoring of forest and rural fires

\begin{tabular}{|c|c|c|c|c|c|c|c|c|c|c|c|c|}
\hline \multirow[t]{4}{*}{ Parameter } & \multirow{2}{*}{\multicolumn{3}{|c|}{$\begin{array}{l}\text { "Status quo", i.e. solely helicopter } \\
\text { use } \\
\text { Scenario } 1\end{array}$}} & \multirow{2}{*}{\multicolumn{3}{|c|}{$\begin{array}{l}\text { "Potential RPA } \\
\text { use" } \\
\text { Scenario } 2 \\
\end{array}$}} & \multirow{2}{*}{\multicolumn{3}{|c|}{ Scenario 3}} & \\
\hline & & & & & & & & & & Scenaric & & \\
\hline & \multicolumn{3}{|c|}{$0 \%$ RPA use } & \multicolumn{3}{|c|}{$25 \%$ RPA use } & \multicolumn{3}{|c|}{$50 \%$ RPA use } & \multicolumn{3}{|c|}{$100 \%$ RPA use } \\
\hline & IV & $\mathrm{mlv}$ & hv & IV & $\mathrm{mlv}$ & hv & IV & $\mathrm{mlv}$ & hv & IV & $\mathrm{mlv}$ & hv \\
\hline \multirow[t]{2}{*}{ Cost-Benefit in terms of area burned } & -0.7 & 6.3 & 14.9 & 4.7 & 8.6 & 14.1 & 10.2 & 15.2 & 21.0 & 8.5 & 17.4 & 26.0 \\
\hline & $-10-5$ & $0-15$ & $5-25$ & $0-25$ & $2-25$ & $4-28$ & $3-50$ & $5-52$ & $7-55$ & $-20-53$ & $-10-62$ & $0-67$ \\
\hline \multirow[t]{2}{*}{ Cost-Benefit in terms of fire suppression costs } & 1.4 & 8.0 & 14.5 & 5.9 & 12.4 & 17.7 & 11.2 & 22.8 & 35.8 & 7.9 & 19.8 & 29.3 \\
\hline & $0-5$ & $0-15$ & $0-25$ & $0-25$ & $6-25$ & $9-28$ & $0-50$ & $10-52$ & $10-52$ & $-20-53$ & $-10-62$ & $0-67$ \\
\hline \multirow[t]{2}{*}{ Cost-Benefit in terms of fatalities } & 0.1 & 1.6 & 3.1 & 2.8 & 5.0 & 8.3 & 3.5 & 7.7 & 12.0 & 2.5 & 7.0 & 10.7 \\
\hline & $-2-5$ & $0-5$ & $0-7.5$ & $0-10$ & $1-15$ & $2-20$ & $0-10$ & $1.5-30$ & $2-40$ & $0-10$ & $1-30$ & $2-50$ \\
\hline \multirow[t]{2}{*}{ Cost-Benefit in terms of injuries } & 0.5 & 2.2 & 5.2 & 2.0 & 4.7 & 7.9 & 4.2 & 7.0 & 11.8 & 3.5 & 7.1 & 10.5 \\
\hline & $-2-5$ & $0-10$ & $0-20$ & $0-10$ & $1-25$ & $2-30$ & $0-20$ & $1.3-30$ & $2.5-45$ & $0-20$ & $1-30$ & $2-45$ \\
\hline
\end{tabular}

$I v$ lowest value, $m / v$ most likely value, $h v$ highest value. Table adapted from Gould et al. (2013)

These methods are often used in evaluations of cost and benefits in incorporating new technology.

A Microsoft Exel $^{\mathrm{TM}}$-based approach developed by Hesse (2000) was used to quantify the triangular distribution model from the three inputs for each parameter (see Table 2); Lowest value, Most likely value and Highest value. A cumulative probability curve (frequency distribution) is given in Fig. 1 (adapted from Gould et al. 2013) showing how the Most likely value influences the shape of the distribution relative to the minimum and maximum values. The output of these (means and standard deviations) were then put through a Monte Carlo simulation approach, to give 10,000 values for use in the economic evaluation.

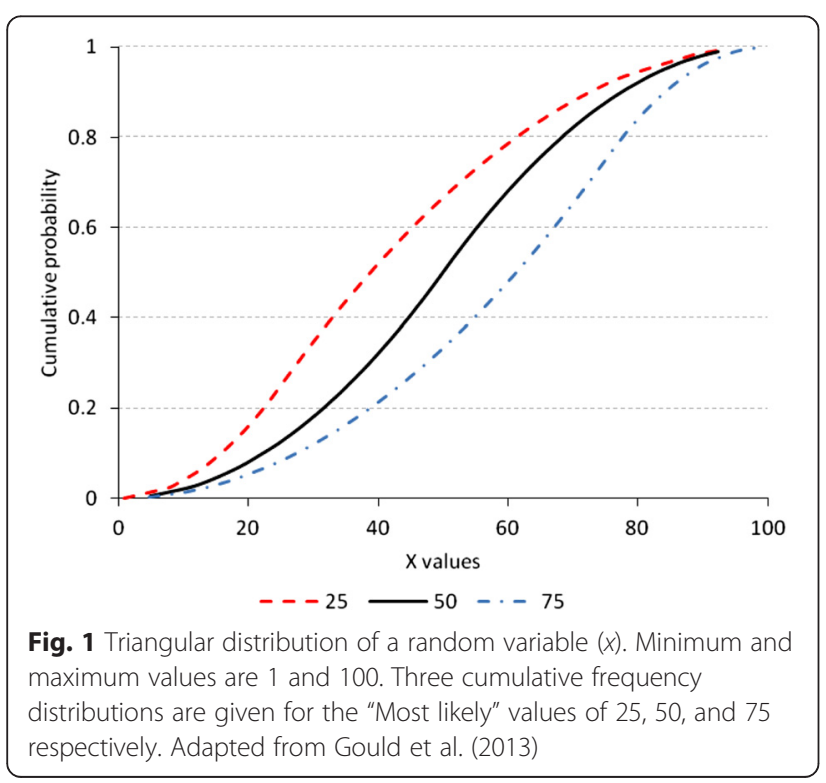

\section{Results}

Incorporation of new technology into wildfire management

A survey investigated the perceived potential benefits of RPA use. In general, the perceptions from the Fire and RPA specialists were positive, with only few negative values ascribed to the lowest value resulting from RPA use (Table 2). The initial question attempted to identify participants' views on the benefit using current technology, i.e. suppression reduction using (or potentially using) thermal or infrared cameras in fire management. This was used as a baseline for the cost benefit analysis.

Of all scenarios including the current approach or status quo, scenario 3 (50\% incorporation of RPA use into aerial fire monitoring) was perceived by the expert participants' to have the greatest potential overall scenario benefits, and was marginally greater than the benefits perceived for scenario 4 (100\% RPA use). This scenario identified a most likely perceived reduction potential of fire suppression costs of $22.8 \%$. This was followed by area (extent) burnt (15.2\%), with reduction in fatalities and injuries (while still of greater benefit than all other scenarios) substantially less at $7.1 \%$ and $7.0 \%$ respectively. The total of percentage reductions for each scenario across all parameters (in decreasing order) was as follows; scenario 3 (50\% RPA use)-52.7\%, scenario 4 (100\% RPA use)-51.3\%, scenario 2 (25\% RPA use)$30.7 \%$, and the scenario 1 (status quo) $-17.1 \%$.

An example of the cumulative probability of the perceived percentage changes for the different scenarios is shown in Fig. 2. In terms of fire suppression costs, the status quo (scenario 1) had a wide distribution of values, hence initially the incorporation of $25 \%$ RPA use was considered to have in approximately $27 \%$ of cases a 


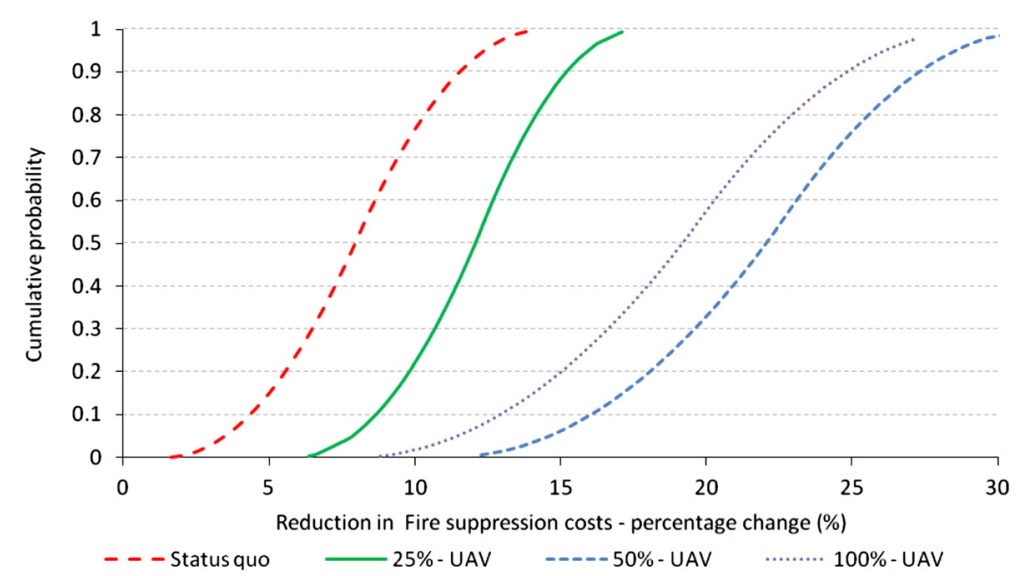

Fig. 2 Cumulative probability distributions for Fire suppression costs as elicited from the combined experts' estimation of percentage change within four scenarios (status quo, 25,50 or $100 \%$ RPA use) for monitoring wildfires

reduction of the area burnt by at least approximately $5 \%$, at $50 \%$ RPA use costs could be further reduced by $10.5 \%$, and at $100 \%$ RPA use such cost could be further reduced by $7 \%$.

\section{Cost-benefit analysis of the incorporation of new technology for forest and rural fire management}

The simulated NPV of the different technologies showed that for wildfire management cost reduction the most cost-beneficial approach was the incorporation of RPAFLIR. NPV becomes positive for RPAs at a use rate of three fires per year by the 8th year. While the thermal camera use did clearly show a positive effect on reducing suppression costs, the NPV only became positive for thermal camera use, when used for at least 17 fires per year by the 10th year, or; at 18 and 19 fires per year (at year 9), or at 20 fires per year (at year 8 ). The estimated return on investment of RPA-FLIR was estimated at 24 fires, whereas the return on investment of thermal camera/helicopter use occurred after 160 fires.

Summary of the average difference in the Net Present Values (NPV) for all fire suppression (not counting the initial purchase costs of RPA-FLIR or Thermal cameras) costs at year 1 between the scenarios 2, 3 and 4 from scenario 1 is given in Table 3 . This specifically considers the cost saving opportunity of helicopters at fires considering the first stage survey participants' elicitation percentages. The greatest return in terms of fire suppression per hectare comes from the incorporation of scenario 3, the utilisation of RPA in $50 \%$ of all potential fire monitoring. Scenario 4, however, resulted in the greatest overall reduction in costs per fire.

The total potential suppression savings (including mortality and injury costs) in terms of the average of costs/fire (using previous 11 years NZFS data source: NZFS Annual reports) are listed below. As the average fire suppression activities (e.g. salaries, machinery \& equipment usage) as per Wu et al. (2009) cost \$1796 per fire, the following potential dollar savings were identified;

- Scenario 2-25\% RPA use-7 \%,

- Scenario 3-50 \% RPA use-23\%, and

- Scenario 4-100 \% RPA use-31\%.

These potential savings include faster mop-up of fires using RPA-FLIR use. Even though expert elicitation put had the best percentage change for scenario 3-50\% RPA use, the analysis indicated the cost saving opportunity of helicopter suppression is potentially higher in Scenario 4. While Scenario 4 had the highest return, the participants noted that having people in helicopters for some of the monitoring has a clear benefit, thus the most optimal RPA-FLIR use is somewhere in between these two scenarios, i.e. $50-100 \%$ of all monitoring efforts.

Table 3 Summary of average difference in scenarios from status quo Scenario 1: Net present value at year 1

\begin{tabular}{lllll}
\hline Research scenario & Cost/fire & Cost/area burnt ha & Mortality and Injury costs/fire & Total savings/fire \\
\hline Scenario 2 & $\$ 109$ & $\$ 172$ & $\$ 13$ & $\$ 122$ \\
Scenario 3 & $\$ 385$ & $\$ 406$ & $\$ 27$ & $\$ 412$ \\
Scenario 4 & $\$ 494$ & $\$ 368$ & $\$ 54$ & $\$ 548$ \\
\hline
\end{tabular}




\section{Discussion}

Financial management issues and concerns are crucial in the incorporation of new technology. Through the use of CBA, and assuming that the imaging capabilities are effectively equivalent between DOC's current thermal cameras and present FLIR technology, the RPA-FLIR platform would offer a far greater return on investment. The cost-opportunity offered by freeing-up helicopter time would transfer a direct average cost saving of up to $31 \%$ in costs for fighting rural and wildland fires. Depending on the availability and implementation of such technology, and assuming that the assumptions made are valid, this could represent an annual saving between \$450,000-\$2,260,000 NZD for rural and wildland fire management in New Zealand. This assumes that both a RPA-FLIR unit and helicopter is available for all fires. While not quantified here, perhaps the most advantageous use of RPA-FLIR is the potential time saved in the support of "mopping-up" tasks at smaller fires where no helicopter support is present.

On average, the return on investment of RPA-FLIR was estimated at 24 fires, whereas the return on investment of thermal camera/helicopter use occurred after 160 fires. RPA-FLIR systems would repay any investment far quicker that the current DOC thermal cameras, and in terms of cost-benefit are clearly worth consideration for further testing by agencies. As the current DOC thermal cameras are sunk costs, and will have an approximate lifetime, it is recommended that these be utilised as often as feasibly possible. While CBA is relatively simple and inexpensive to conduct, it can have unintended consequences if investment decisions are made solely on it alone. More testing and analysis requirements should be established and met prior to any implementation of RPA technology.

The economics of monitoring rural and wildland fires has changed over the last couple of decades. Previous costs for both thermal cameras and aerial monitoring of wildland rural fires costs were in the many tens of thousands of dollars. Both FLIR and RPA technology have brought this down to a few to several thousand dollars just for the initial purchase costs. FLIR technology has recently been linked with mobile phone technology and software applications, with costs currently down to less than $\$ 500$. Thus the CBA figures with the best ROI calculated for this paper will soon be "out-of-date", and thus be just a snap-shot in time, or at least represent a conservative estimate of returns. There is a clear need for active cost-return, and ROI analysis for new emerging technologies to see if they merit further testing.

\section{New technology-and its implementation}

Change is constant and its speed appears to be increasing, perhaps indicative if not of the decreasing costs of technology then certainly its accessibility (Shanks and Tay 2001; Ederington and McCalman 2008). Groen and Walsh (2013) noted that the science and technology of emerging technologies (such as RPA robotics) are clearly far ahead of any due consideration of their commercial, policy, environmental, ethical and societal implications. Emerging technologies are, by definition, not fully developed, and thus arguably are primarily appropriate for operational agencies only for trialling or testing. While the general focus by rural and wildland fire management is not on emerging technology, it is contended that just as thermal cameras were incorporated into operations, there is a clear need to consider trialling of key emerging technology such as RPAs.

The implementation and roll-out of an updated technology would have additional costs, thus a key recommendation would be to test capabilities in further trial studies, with a small number of units. It is suggested that a standard protocol for testing and the incorporation of new technology is used and incorporated under a project management framework.

\section{Use of remote sensing technology}

The current use of the DOC thermal cameras with an average of 2.95 fires per unit per year indicates that on perceived cost reduction alone for wildfire management, it is unlikely that they confer an effective return on their investment if considered in purely monetary terms. The professional rural fire managers indicated that $6.3 \%$ of potential helicopter time is in use for thermal monitoring, compared with $13.7 \%$ for all forms of visual monitoring of fires while using helicopters (Christensen 2015, in submittance). While such values are relatively small, they are a perhaps a useful indicator of the longer-term wildfire management efforts as opposed from the initial attack efforts. Helicopters are a hugely useful aerial platform for wildland rural fire work, though it is now clearly important to consider the potential integration of RPAs into wildland rural fire management.

There is a noted trade-off between pre-suppression and suppression (including 'mop-up') costs (Mercer et al. 2008; Florec et al. 2012), with reductions in one stage likely to be associated with increases in the other (Wu et al. 2009). This paper recognises such a relationship, though targets the implementation in technology that have both an initial reduced cost of investment as well as a released cost-opportunity value. By the addition of RPAs, greater and more cost-effective allocation of key resource capabilities can occur. This specialisation can only be enabled by the implementation of new technology.

\section{Conclusion}

RPAs are currently not used for wildland fire fighting in New Zealand, though are being tested by the New 
Zealand Fire Service for urban use. Thermal cameras and imaging, however, have been incorporated in wildland fire monitoring from the 1970s (Fulton and Mason 1982), though only established in New Zealand within the previous decade. Plucinski and Pastor (2013) noted that there is an immense value of ortho-rectified aerial IR imagery for the management of wildland fires. The comparison of the cost-effectiveness of aircraft in fire suppression in New Zealand, has shown that improvement has occurred with the introduction of new aircraft (Fogarty and Smart 1996). While the DOC fire-related helicopter costs are relatively small in comparison to the overall fire-related expenditure, RPAs if implemented and managed appropriately, could well improve the cost effectiveness of such fire fighting efforts. While more aerial fire-fighting resources do not necessarily result in faster fire containment (Plucinski et al. 2012), the introduction of specific aerial monitoring by RPAs, e.g. in "mop-up" and "cold-trailing" activities is likely to obviate the need for longer ground operations or repeat visits.

Stephenson et al. (2013) noted the need to develop consistent values for environmental damage done by wildfires. The $C+N V C$ model is primarily used to examine the relationship of prescribed burning practices relative to future suppression costs, and shows that prescribed burning (within the current or recent fire seasons) decreases wildfire intensity, and thus increases the probability of successful suppression (Fernandes and Botelho 2003; Florec et al. 2012). The $C+N V C$ model with the incorporation of $\mathrm{Wu}$ et al. (2009) outputs was adapted for use in this paper, it was shown to give a useful approximation of the difference between scenarios, and could be further utilised with specific wildfire management data (i.e. pre-suppression efforts-such as prescribed burning) if and where available. The use of this model by agencies could lead to clearer business decision making and project management approaches, which is likely to have a direct cost saving in this field.

It is recommended that:

- Further testing of RPA and FLIR application in wildland rural fire fighting is warranted. It is also suggested that a project management approach is used in the testing of new technologies. Further research questions arise such as: is the quality of data useful for real-time monitoring of wildfires?

- The existing (DOC's and other agencies') thermal cameras are utilised as often as logistically and feasibly possible, to return as much of their investment costs.

- In order that clearer analysis on costs and benefits can occur, improved financial and operational accounting and access to data relating to wildland rural fire fighting efforts is warranted.
- Central capture of all New Zealand wildland rural fire data, including spatial information, costs, and resources used is made available for public use.

\section{Endnotes}

${ }^{1}$ The International Civil Aviation Organization (ICAO) uses the terms Remotely Piloted Aircraft (RPA) and Remotely Piloted Aircraft System (RPAS), as does the New Zealand Civil Aviation Authority (CAA).

${ }^{2} C=$ cost, $N V C=$ Net Value Change.

\section{Competing interests}

The author declares that he has no competing interests.

\section{Acknowledgements}

Thanks go to the following people; my academic supervisors-Dr Michaela Balzarova, and Dr David Cohen for the review of the work as a dissertation. Thanks also to Dr Jim Gould for discussion and his approval to utilise and adapt the evaluation approach developed for research benefiting the Canadian Forest Fire Danger Rating System. I acknowledge and appreciate the support of my employer; the Department of Conservation, and specifically my Manager Simon Kelton. Dawn Smith was instrumental in obtaining fire-related costs for this project. Bruce Janes, Tom Barr, and Dean Strachan provided useful discussion on thermal camera use and capabilities. Tom Barr, Brenton Wilson and Emma Griffen provided the thermal camera use data. Members of the RPA and Wildland fire management online fraternity; Eric Lien, Doug Campbell, Joachim Dreibach, David Cant, F. Javier Garcia Garcia, Patrick "Lucidity" of the RPA Roswell Test Flight Team, and DOC staff; Dean Strachan and Earl Rewi for discussion on RPA and FLIR use and potential at wildland fires. I am grateful for suggestions from two anonymous reviewers which improved this article. Finally, I would like to thank all the survey participants, their input was critical to the value of this article and the completion of my dissertation. I acknowledge the previous work completed by researchers and compilers of fire data, which allowed the analyses within this article to take place.

Received: 2 April 2015 Accepted: 20 July 2015

Published online: 04 September 2015

\section{References}

Anadón, LD, Bosetti, V, Bunn, M, Catenacci, M, \& Lee, A. (2012). Expert judgments about RD and $\mathrm{D}$ and the future of nuclear energy. Environmental Science and Technology, 46(21), 11497-11504.

Christensen, BR. (2015). Technological advances in rural and wildland fire management as determined using organisational knowledge. New Zealand Journal of Forestry, 60(2), 29-32.

Donovan, GH, \& Rideout, DB. (2003). A reformulation of the Cost Plus Net value Change ( $C+N V C$ model of wildfire economics. Forest Science, 49(2), 318-323.

Ederington, J, \& McCalman, P. (2008). Endogenous firm heterogeneity and the dynamics of trade liberalization. Journal of International Economics, $74,422-440$.

Fernandes, PM, \& Botelho, HS. (2003). A review of prescribed burning effectiveness in fire hazard reduction. International Journal of Wildland Fire, 12, 117-128.

Florec, V, Pannell, D, Burton, M, Kelso, J, Mellor, D, \& Milne, G. (2012). Economic analysis of bushfire management programs: a Western Australian perspective. In RP Thornton \& L W Wright (Eds.), Proceedings of bushfire CRC and AFAC conference research forum, 28 August 2012. Bushfire CRC: Perth Australia.

Fogarty, L, \& Smart, P. (1996). Comparison of the cost-effectiveness of some aircraft used for fire suppression (Fire Technology Transfer Note No. 8, p. 9).

Fulton, RW, \& Mason, GF. (1982). Night vision electro-optics technology transfer: a decade of activity. The Journal of Technology Transfer, 7(1), 35-53.

Ganewatta, G. (2008). The economics of bushfire management. In J Handmer \& K Haynes (Eds.), Community bushfire safety (pp. 151-159). Victoria: CSIRO Publishing. Collingwood.

Garthwaite, PH, Kaldane, JB, \& O'Hagan, A. (2005). Statistical methods for eliciting probability distribution. Journal of the American Statistical Association, 100, 680-701. 
Gerbert, K, Calkin, DE, Huggett, RJ, \& Abt, K (2008). Toward a unified economic theory of fire program analysis with strategies for empirical modelling. In TP Holmes, JP Prestemon, \& K Abt (Eds.), The economics of forest disturbances: wildfires, storms, and invasive species. (pp. 295-322). Dordrecht: Springer.

Gould, JS, Patriquin, MN, Wang, S, McFarlane, BL, \& Wotton, M. (2013). Economic evaluation of research to improve the Canadian forest fire danger rating system. Forestry, 86, 317-329.

Groen, AJ, \& Walsh, ST. (2013). Introduction to the field of emerging technology management. Creativity and Innovation Management, 22(1), 1-5.

Hesse, R. (2000). Triangle distribution: Mathematica link for Excel (Decision Line, May 2000, pp. 12-14).

Hesseln, H, Amacher, GS, \& Deskins, A. (2010). Economic analysis of geospatial technologies for wildfire suppression. International Journal of Wildland Fire, 19(4), 468-477

Hyytiäinen, K, \& Haight, RG. (2010). Evaluation of forest management systems under risk of wildfire. European Journal of Forest Research, 129, 909-919.

Knol, AB, Slottje, P, van der Sluijs, JP, \& Lebret, E. (2010). The use of expert elicitation in environmental health impact assessment: a seven step procedure. Environmental Health, 9, 19. doi:10.1186/1476-069X-9-19.

Kumar, M, Cohen, K, \& Homchaudhuri, B. (2011). Cooperative control of multiple uninhabited aerial vehicles for monitoring and fighting wildfires. Journal of Aerospace Computing, Information, and Communication, 8(1), 1-16.

Lankoandé, MD. (2005). Three essays on wildfire economics and policy. Washington State University: Unpublished Doctor of Philosophy thesis. School of Economic Sciences.

Laupacis, A, Feeny, D, Detsky, AS, \& Tugwell, PX. (1992). How attractive does a new technology have to be to warrant adoption and utilization? Tentative guidelines for clinical and economic evaluations. Canadian Medical Association Journal, 146(4), 473-481.

Mercer, DE, Haight, RG, \& Prestemon, JP. (2008). Analyzing trade-offs between fuels management, suppression, and damages from wildfire. In TP Holmes (Ed.), The economics of forest disturbances; wildfires, storms and invasive species (pp. 247-272). Dordrecht: Springer Science + Business Media.

Merino, L, Caballero, F, Martinez-de-Dios, JR, Maza, I, \& Ollero, A. (2012). An unmanned aircraft system for automatic forest fire monitoring and measurement. Journal of Intelligent and Robotic Systems, 65, 533-548.

MOT (Ministry of Transport). (2008). The social cost of road crashes and injuries: June 2008. Wellington: Ministry of Transport. New Zealand Government.

Pearce, HG, Hamilton, RW, \& Millman, RI. (2004). Fire behaviour and firefighter safety implications associated with the Bucklands Crossing Fire burnover of 24 March 1998 (Forest Research Bulletin No. 197, Forest and Rural Scientific and Technical Series, Report No. 4, p. 62). Forest Research, Rotorua, in association with the New Zealand Service Commission and National Fire Authority, Wellington

Plucinski, MP, \& Pastor, E. (2013). Criteria and methodology for measuring aerial wildfire suppression. International Journal of Wildland Fire, 22(8), 1144-1154.

Plucinski, M, McCarthy, GJ, Hollis, JJ, \& Gould, JS. (2012). The effect of aerial suppression on the containment time of Australian wildfires estimated by fire management personnel. International Journal of Wildland Fire, 21, 219-229.

Rango, A, Laliberte, A, Steele, C, Herrick, JE, Bestelmeyer, B, Schmugge, T, Roanhorse, A, \& Jenkins, V. (2006). Using remotely piloted aircraft for rangelands: current applications and future potentials. Environmental Practice, 8(3), 159-168

Royo, P, Pastor, E, Solé, M, Lema, JM, López, J, \& Barrado, C. (2011). UAS architecture for forest fire remote sensing (International symposium on remote sensing of environment. ISPRS Proceedings 2011. Sydney, pp. 1-4). http:// upcommons.upc.edu/e-prints/bitstream/2117/16549/1/ 211104015final00187.pdf.

Runge, MC, Converse, SJ, \& Lyons, JE. (2011). Special issue article: adaptive management for biodiversity conservation in an uncertain world. Which uncertainty? Using expert elicitation and expected value of information to design an adaptive program. Biological Conservation, 144, 1214-1223.

Shanks, G, \& Tay, E. (2001). The role of knowledge management in moving to a customer-focused organization. In Global co-operation in the new millennium. The 9th European conference on information systems, June 27-29, 2001, Bled, Slovenia

Stephenson, C, Handmer, J, \& Betts, R. (2013). Estimating the economic, social and environmental impacts of wildfires in Australia. Environmental Hazards, 12(2), 93-111
The Treasury. (2005). Cost benefit analysis primer. The Treasury. New Zealand Government. http://www.treasury.govt.nz/publications/guidance/planning/ costbenefitanalysis/primer/cba-primer-v12.pdf

van Dorp, JR, \& Kotz, S. (2002). A novel extension of the triangular distribution and its parameter estimation. The Statistician, 51(1), 63-79.

Wren, J, \& Barrell, K. (2010). The costs of injury in New Zealand methods for prioritising resource allocation: a background briefing paper to inform the evaluation of the New Zealand injury prevention strategy. Wellington, New Zealand: New Zealand Injury Prevention Secretariat, ACC.

Wu, J, Kaliyati, W, \& Sanderson, K. (2009). The economic cost of wildfires (Business and Economic Research Ltd (BERL). New Zealand Fire Service Commission Research Report Number 99). Wellington: New Zealand Fire Service.

\section{Submit your manuscript to a SpringerOpen ${ }^{\odot}$ journal and benefit from:}

- Convenient online submission

- Rigorous peer review

- Immediate publication on acceptance

- Open access: articles freely available online

- High visibility within the field

- Retaining the copyright to your article

Submit your next manuscript at $>$ springeropen.com 